\title{
Mode-Based Transport Sustainability: A Comparative Study of Taipei and Kaohsiung Cities
}

\author{
Tzay-An Shiau ${ }^{1} \&$ Quan-Kai Peng ${ }^{1}$ \\ ${ }^{1}$ Department of Harbor and River Engineering, National Taiwan Ocean University, Keelung, Taiwan \\ Correspondence: Tzay-An Shiau, Department of Harbor and River Engineering, National Taiwan Ocean \\ University, 2, Pei-Nein Road, Keelung, Taiwan. Tel: 886-22-462-2192 ext 6141. E-mail: sta@mail.ntou.edu.tw
}

Received: August 22, 2012 Accepted: Spetember 13, 2012 Online Published: September 26, 2012

doi:10.5539/jsd.v5n10p68 URL: http://dx.doi.org/10.5539/jsd.v5n10p68

\begin{abstract}
Mode shifting is an effective solution to improve transport sustainability. This study developed an indicator system for measuring mode-based transport sustainability at the local level, and the results provided a basis for evaluating the proposed improvement solutions. A case study of Taipei and Kaohsiung confirmed that the mode-based transport sustainability model could highlight which mode provided the most superior transport sustainability and which indicator or aspect could be improved to enhance the transport sustainability of the two cities. The findings from Taipei and Kaohsiung revealed that the use of Mass Rapid Transit (MRT) and bicycles significantly improved transport sustainability, but that the effects of motorcycle use on transport sustainability varied according to local circumstances. Analysis of four transport sustainability improvement scenarios indicated that building bicycle exclusive lanes would have significant environmental and social benefits both in Taipei and Kaohsiung. Increasing parking fees for cars and motorcycles would have a relatively insignificant effect on improving sustainability in Taipei City. Constructing an infrastructure for electric motorcycles in Kaohsiung would provide the most significant improvement to transport sustainability of any of the four scenarios.
\end{abstract}

Keywords: mode shifting, transport sustainability, input-output model, electric motorcycle, environmental impacts

\section{Introduction}

Improving transport sustainability has become a focus of transport planning in response to global climate change around the world. Most of the literature has been concerned with transport sustainability at the national level. For example, the European Environment Agency (EEA) proposed an indicator system for measuring the transport sustainability of EU countries in 2000 called the "Transport and Environment Reporting Mechanism" (TERM) (EEA, 2001). Additionally, the EEA has reported annually on the measurements of transport sustainability indicators (subject to data availability; some countries do not provide complete measurements) (EEA, 2011). Some studies have focused on transport sustainability at the local level. For example, Shiau (2012) constructed a sustainability compound index (SCI) to measure transport sustainability of a city, and 15 improvement strategies taken from the three categories of land use planning, shifting modes, and using clean energy were evaluated for Taipei City. Amekudzi, Khisty, and Khayesi (2009) proposed a conceptual sustainability footprint model and illustrated its application in different cities. The authors concluded that mode shifting is an effective solution to improve transport sustainability. Givoni (2007) compared two modes of aircraft and high-speed train between London and Paris and concluded that substituting an aircraft seat with a high-speed train seat would reduce environmental impacts. Carse (2011) proposed an indicator system for measuring the transport quality of life in Glasgow and Manchester; the results showed that Light Rapid Transport is better than buses in terms of transport quality of life. Litman (2007) indicated that motor vehicle travel is sometimes used as a sustainability indicator, assuming that motorized travel is an unsustainable way of transportation. An opposing viewpoint was expressed by Dudson (1998), who argued that high levels of motorized travel can be sustainable with technological improvements in vehicle and roadway designs. Kennedy (2002) compared the sustainability of public and private transportation systems in the Greater Toronto Area and concluded that to achieve overall sustainable development, a transportation system has to be flexible and adaptable and a combination of different modes is required. 
The previous studies have indicated that a comparison between different modes is a crucial basis for introducing mode-shifting strategies. The focus of the present study is to develop an indicator system for measuring mode-based transport sustainability at the local level; the results provide a basis for evaluating possible solutions to improve transport sustainability. A comparative study of Taipei City and Kaohsiung City in Taiwan is also illustrated.

\section{Mode-based Transport Sustainability}

Transport sustainability has become a common vision for the central and local governments in Taiwan. This study adopted a broad scope of transport sustainability as defined by the European Council of Ministers of Transport (ECMT, 2004). The ECTM summarized the "characteristics of transport sustainability" in the following list:

1) It allows the basic access and development needs of individuals, companies and society to be met safely and in a manner consistent with human and ecosystem health, and promotes equity within and between successive generations.

2) It is affordable, operates fairly and efficiently, offers a choice of transport mode and supports a competitive economy, as well as balanced regional development.

3) It limits emissions and waste within the planet's ability to absorb them, uses renewable resources at or below their rates of generation, and uses non-renewable resources at or below the rates of development of renewable substitutes, while minimizing the impact on the use of land and the generation of noise.

This study decomposed the framework of mode-based transport sustainability indicators into the aspects of economy, environment, and society according to the definition of transport sustainability (ECMT, 2004). The economic aspect is composed of four indicators: average travel time, average travel cost, average infrastructure cost, and average industrial backward linkage effect. The environmental aspect is composed of three indicators: $\mathrm{CO}_{2}$ emission intensity, air pollutant emission intensity, and energy intensity. The social aspect is composed of traffic accident rate and traffic noise indicators. The Delphi method as reviewed by Clayton (1997) was used to pool ideas in generating the indicator system. The decision group consisted of equal numbers of experts (18 total) chosen from among academic researchers, Non-Governmental Organization (NGO) staff members, and government officials. During the Delphi survey process, the indicator "traffic noise" induced a broad discussion. Some experts argued that this indicator should be classified into the environmental aspect. However, most of the experts claimed that traffic noise causes stress or anger in some people, and thus induces social problems; they claimed that the traffic noise indicator should be classified into the social aspect.

The definitions and measurements of the indicators can be summarized as follows:

1) Average travel time: This indicator is defined as unit travel time for trip makers using a particular mode, and is measured by calculating average in-vehicle time and out-of-vehicle time, as shown in Equation 1.

$$
A T T=1 / A V+O V T / A T L
$$

where $A T T$ is the travel time per vehicle-kilometer (VKM);AV is the average speed of vehicle; $O V T$ is the out-of-vehicle time; and $A T L$ is the average trip length.

2) Average travel cost: This indicator is defined as unit travel cost for trip makers using a particular mode. Private modes are measured by using Equation 2 and public transit trips are reflected by fares.

$$
A T C_{p}=(E C / E I+N E C / T V K T) / L F
$$

where $A T C_{p}$ is the travel cost per passenger-kilometer (PKM) for private modes; $E C$ is energy cost; $E I$ is energy intensity; $N E C$ is non-energy cost, including maintenance cost, depreciation cost, parking cost, etc. TVKT is total lifetime VKM traveled; and $L F$ is the loading factor for private modes.

3) Average infrastructure cost: This indicator is defined as unit infrastructure cost for trip makers using a particular mode. Qin et al. (1996) categorized highway infrastructure cost into capital cost and non-capital cost for private modes and buses; and categorized rail infrastructure cost into right-of-way cost, rail cost, terminal cost, and train cost. The infrastructure cost per VKM is transformed into the infrastructure cost per PKM by dividing the loading factor of the modes.

4) Average industrial backward linkage effect: This indicator is defined as unit industrial backward linkage effect caused by trip makers using a particular mode, and is measured by using an input-output model (Leontief, 1986), as shown in Equation 3.

$$
X=(I-A)^{-1} D
$$


where $X$ denotes the production matrix; $I$ denotes the identity matrix; $A$ denotes the input coefficient matrix; and $D$ denotes the demand matrix. The total effect is divided by PKM.

5) $\mathrm{CO}_{2}$ emission intensity: This indicator is defined as unit $\mathrm{CO}_{2}$ emissions caused by trip makers using a particular mode. The measurement of $\mathrm{CO}_{2}$ emission intensity is shown in Equation 4.

$$
A C O_{2}=C E C \times E I / L F
$$

where $\mathrm{ACO}_{2}$ is $\mathrm{CO}_{2}$ emission per PKM; and $\mathrm{CEC}$ is the carbon emission coefficient.

6) Air pollutant emission intensity: This indicator is defined as unit air pollutant emissions caused by trip makers using a particular mode. The measurement of air pollutant emission intensity is shown in Equation 5.

$$
A P=P E C \times E I / L F
$$

where $A P$ is air pollutant emissions per PKM; and $P E C$ is the coefficient of air pollutant emissions.

7) Energy intensity: This indicator is defined as unit energy consumption, and is measured by energy consumption divided by PKM.

8) Traffic accident rate: This indicator is defined as unit traffic accidents, and is measured by number of fatalities caused by traffic accidents per PKM.

9) Traffic noise: This indicator is defined as a simplified transport quality of life for trip makers using a particular mode, and is measured by passenger car equivalents for noise, as shown in Equation 6.

$$
N P C E_{m}=10^{\left(d B_{m}-d B_{c}\right) / 10}
$$

where $N P C E_{m}$ denotes the passenger car equivalents of noise produced by mode $m ; d B_{m}$ denotes the decibels produced by mode $m$; and $d B_{c}$ denotes the decibels produced by a passenger car.

The hierarchical structure of the indicator system is shown in Figure 1. 


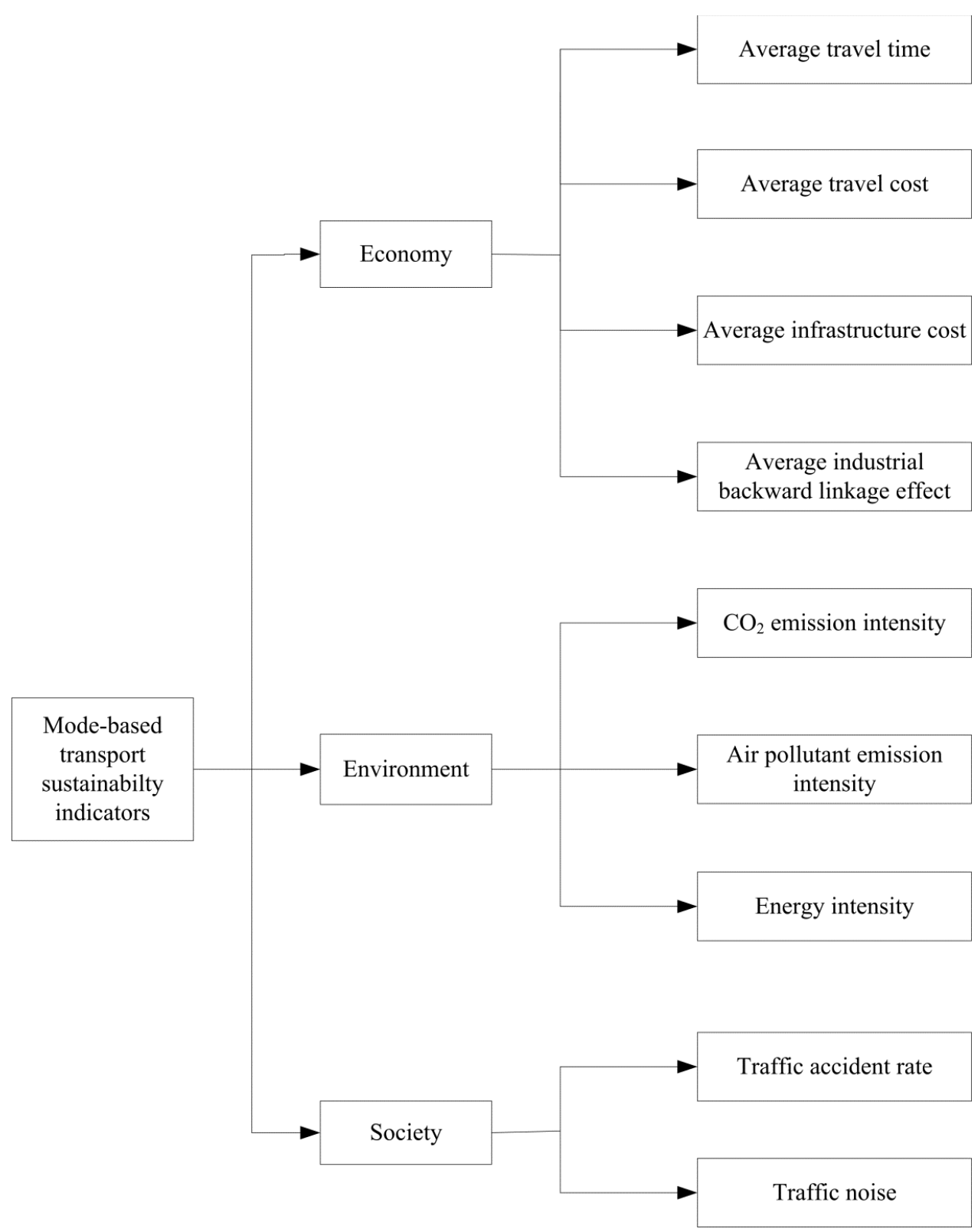

Figure 1. The hierarchical structure of mode-based transport sustainability indicators

\section{A comparative Study of Taipei City and Kaohsiung City}

\subsection{Baseline Comparison}

Taipei City, located in northern Taiwan, is the capital of Taiwan. Total population and population density are 2.6 million and 9.6 thousand $/ \mathrm{km}^{2}$ respectively. Service industries comprise the major part of the economy (providing $81.3 \%$ of Taipei-area jobs); public facilities and utilities are widely distributed. Taipei Mass Rapid Transit (MRT) has been expanded to $110 \mathrm{~km}$ of operation network and provides over 1.5 million trips per day.

Kaohsiung City is also a municipality of Taiwan located in southern Taiwan. Service and manufacturing industries dominate its economy (providing $67.6 \%$ and $31.4 \%$ of Kaohsiung-area jobs respectively). Total population and population density are 1.5 million and 9.9 thousand $/ \mathrm{km}^{2}$ respectively. Kaohsiung MRT has only $41 \mathrm{~km}$ of operation network and provides about 0.15 million trips per day. Motorcycle use is popular in Taiwan; there are about 1.1 million and 1.2 million motorcycles owned by Taipei citizens and Kaohsiung citizens respectively. The market share of motorcycles for passenger transportation in Taipei City and Kaohsiung City is $41.4 \%$ and $63.8 \%$ respectively.

Both Taipei City and Kaohsiung City have more than one million inhabitants each, making the cities suitable 
candidates for developing MRT systems. Additionally, both cities have about the same population density. Because of these similarities, these cities provide a fair basis for comparing mode-based transport sustainability. This study measured the transport sustainability of the following modes: motorcycle, passenger car, bicycle, bus, and MRT. Nine indicators related to mode-based transport sustainability (Figure 1) were measured using the measurements described in Section 2 and compared for Taipei City and Kaohsiung City. The results showed that motorcycles have comparative disadvantages in terms of traffic safety (the motorcycle traffic accident rate is higher than the accident rates for passenger cars, buses, and MRT in Taipei) and environmental impacts (the air pollutant emission intensity of motorcycles is the highest of all the transport modes in both cities), but have comparative advantages in travel time (motorcycles have the shortest travel time in both cities) and door-to-door service; therefore, a large proportion of trips are made by motorcycle. Bicycles are the most environmentally friendly mode of transport in terms of air pollutant emissions, $\mathrm{CO}_{2}$ emissions, and energy intensity, but they are also the most dangerous mode (the bicycle traffic accident rate is 1.72 fatalities/100 million PKM in Taipei City and 0.75 fatalities/100 million PKM in Kaohsiung City). Taipei MRT has comparative advantages in traffic safety ( 0.00 fatalities $/ 100$ million PKM), environmental impacts (the air pollutant emission intensity is 0.20 $\mathrm{g} / \mathrm{PKM}$ ), and industrial backward linkage effect (24.94 NTD/PKM), but has comparative disadvantages in infrastructure cost (8.61 NTD/PKM). Compared to Taipei MRT, Kaohsiung MRT operations have not yet reached their optimum economies of scale; therefore, Kaohsiung MRT has comparative disadvantages in infrastructure cost (20.29 NTD/PKM), $\mathrm{CO}_{2}$ emission intensity (112.44 g/PKM), and energy intensity (0.37 LOE/10 PKM). Table 1 and Table 2 show the results and reveal that the same mode performs differently in terms of transport sustainability in the two cities.

Table 1. Mode-based transport sustainability of Taipei City (1)

\begin{tabular}{cccccc}
\hline Indicator & Motorcycle & Passenger car & Bicycle & Bus & MRT \\
\hline Average travel time (Min./VKM) & 2.58 & 2.82 & 6.40 & 4.66 & 3.76 \\
Average travel cost (NTD/PKM) & 4.20 & 7.63 & 0.63 & 1.86 & 2.56 \\
Average infrastructure cost (NTD/PKM) & 0.16 & 0.34 & 1.15 & 0.09 & 8.61 \\
Average industrial backward linkage effect (NTD/PKM) & 6.48 & 10.95 & 3.26 & 3.70 & 24.94 \\
$\mathrm{CO}_{2}$ emission intensity (g/PKM) & 60.47 & 114.03 & 0.00 & 56.80 & 32.14 \\
Air pollutant emission intensity (g/PKM) & 4.45 & 4.13 & 0.00 & 0.83 & 0.20 \\
Energy intensity (LOE/10 PKM) & 0.23 & 0.40 & 0.00 & 0.20 & 0.11 \\
Traffic accident rate (number of fatalities/100 million PKM) & 0.66 & 0.09 & 1.72 & 0.10 & 0.00 \\
Traffic noise (number of passenger cars) & 3 & 1 & $1 / 10,000$ & 10 & 2 \\
\hline
\end{tabular}

Table 2. Mode-based transport sustainability of Kaohsiung City (1)

\begin{tabular}{cccccc}
\hline Indicator & Motorcycle & Passenger car & Bicycle & Bus & MRT \\
\hline Average travel time (Min./VKM) & 2.55 & 2.69 & 6.40 & 4.73 & 4.27 \\
Average travel cost (NTD/PKM) & 4.20 & 7.63 & 0.63 & 1.26 & 3.10 \\
Average infrastructure cost (NTD/PKM) & 0.16 & 0.34 & 1.15 & 0.13 & 20.29 \\
Average industrial backward linkage effect (NTD/PKM) & 6.48 & 10.95 & 3.26 & 3.14 & 53.86 \\
$\mathrm{CO}_{2}$ emission intensity (g/PKM) & 60.47 & 114.03 & 0.00 & 85.60 & 112.44 \\
Air pollutant emission intensity (g/PKM) & 4.45 & 4.13 & 0.00 & 1.46 & 0.71 \\
Energy intensity (LOE/10 PKM) & 0.23 & 0.40 & 0.00 & 0.31 & 0.37 \\
Traffic accident rate (number of fatalities/100 million PKM) & 0.39 & 0.73 & 0.75 & 0.07 & 0.00 \\
Traffic noise (number of passenger cars) & 3 & 1 & $1 / 10,000$ & 10 & 2 \\
\hline
\end{tabular}

This study applied the Analytic Hierarchy Process (AHP) (Saaty 1980) to construct the weighting scheme of the mode-based transport sustainability indicators. The analytical steps were as follows:

1) Structuring the indicator hierarchy

Figure 1 shows the hierarchical structure of the mode-based transport sustainability indicators. 
2) Constructing a set of pair-wise comparison matrices

A 1-9 scale was used to elicit preferences by constructing a set of pair-wise comparison matrices $A(n \times n)$. The first pair-wise comparison matrix $(3 \times 3)$ was done in terms of preference of one aspect over the other in Figure 1 . Subsequently, a $3 \times 3$ pair-wise comparison matrix was done in terms of preference of one indicator over the other under the aspect of environment. The same procedure was done under the other aspects.

3) Estimating the vector of weights

Solving the characteristic equation (Equation 7) to obtain the largest eigenvalue $\lambda_{\max }$; the corresponding eigenvector $w$ is the vector of weights.

$$
(A-\lambda I) w=0
$$

where $I$ is the unit matrix.

4) Checking the consistency of preferences

The consistency test calculates the Consistency Index (CI) first (Equation 8). Subsequently, The Consistency Ratio (CR) is defined as CI divided by Random Index (RI); where RI is calculated from the average CI of 1,000 random samples.

$$
C I=\frac{\lambda_{\max }-n}{n-1}
$$

Saaty (1980) suggests the threshold: $C R \leq 0.1$ to check the consistency of pair-wise comparison matrices.

5) Calculating the indicator weights

Applying the linear additive decomposition principle (Equation 9) to calculate indicator weights allocated from the corresponding aspect.

$$
w_{i}=\sum_{j=1}^{n} w_{i j}
$$

where $w_{i}$ is the weight of aspect $i ; w_{i j}$ is the weight of criterion $j$ under the aspect $i$.

The AHP application determined the indicator weights given by each representative of the decision group. The compromised indicator weights are listed in Table 3. The three most important indicators determined by the decision group were average travel time (0.187); traffic accident rate $(0.162)$; and traffic noise $(0.142)$.

Table 3. Criteria weights

\begin{tabular}{ccc}
\hline Aspect & Criteria & Weights \\
\hline \multirow{3}{*}{ Economy } & Average travel time (Min./VKM) & 0.187 \\
& Average travel cost (NTD/PKM) & 0.053 \\
& Average infrastructure cost (NTD/PKM) & 0.053 \\
& Average industrial backward linkage effect (NTD/PKM) & 0.053 \\
\hline \multirow{2}{*}{ Environment } & $\mathrm{CO}_{2}$ emission intensity (g/PKM) & 0.117 \\
& Air pollutant emission intensity (g/PKM) & 0.117 \\
\hline \multirow{2}{*}{ Society } & Energy intensity (LOE/10 PKM) & 0.116 \\
& Traffic accident rate (number of fatalities/100 million PKM) & 0.162 \\
\hline
\end{tabular}

Using Equation 10 and Equation 11, mode-based transport sustainability measurements can be aggregated, as shown in Table 4.

$$
A_{k j}=\sum_{i} W_{i} E_{i j}, \forall j
$$

where $A_{k j}$ is the normalized performance of aspect $k$ for mode $j$; $W_{i}$ is the weight of indicator $i$; and $E_{i j}$ is the normalized performance of indicator $i$ for mode $j$.

$$
T S_{j}=\sum_{k} W_{k} A_{k j}, \forall j
$$


where $T S_{j}$ represents the transport sustainability for mode $j ; W_{k}$ represents the weight of aspect $k ; A_{k j}$ represents the normalized performance of aspect $k$ for mode $j$.

Mode-based transport sustainability measurements indicate that, of the five modes analyzed, MRT performs the best ( $T S=0.751$ for Taipei City, and $T S=0.647$ for Kaohsiung City), bicycles are second ( $T S=0.492$ for Taipei City, and $T S=0.520$ for Kaohsiung City), and motorcycles perform the worst in terms of transport sustainability in Taipei City $(T S=0.438$ ). Regarding transport sustainability in Kaohsiung City, MRT performs the best, bicycles are second, but motorcycles are third (in contrast to their performance in Taipei: the worst out of five modes). The implications of this result are that measures should be tailored to suit local circumstances for improving transport sustainability.

Table 4. Mode-based transport sustainability of Taipei and Kaohsiung Cities (2)

\begin{tabular}{cccccc}
\hline Aspect & Motorcycle & Passenger car & Bicycle & Bus & MRT \\
\hline \multirow{2}{*}{ Economy } & $0.546^{\mathrm{a}}$ & 0.526 & 0.000 & 0.248 & 0.565 \\
& $(0.550)^{\mathrm{b}}$ & $(0.544)$ & $(0.000)$ & $(0.239)$ & $(0.759)$ \\
\hline \multirow{2}{*}{ Environment } & 0.298 & 0.025 & 1.000 & 0.606 & 0.800 \\
& $(0.298)$ & $(0.025)$ & $(1.000)$ & $(0.383)$ & $(0.311)$ \\
\hline \multirow{2}{*}{ Society } & 0.477 & 0.867 & 0.467 & 0.526 & 0.907 \\
& $(0.587)$ & $(0.615)$ & $(0.560)$ & $(0.533)$ & $(0.907)$ \\
\hline \multirow{2}{*}{ Transport sustainability } & 0.438 & 0.454 & 0.492 & 0.458 & 0.751 \\
& $(0.473)$ & $(0.384)$ & $(0.520)$ & $(0.379)$ & $(0.647)$ \\
\hline
\end{tabular}

Notes: ${ }^{a}$ denotes figures for Taipei City. ${ }^{\mathrm{b}}$ denotes figures for Kaohsiung City

\subsection{Scenarios of Sustainable Transport Strategies}

This study proposed four scenarios for improving transport sustainability, including two for Taipei City and two for Kaohsiung City as follows:

\section{1) Scenario $T 1$ : Building bicycle exclusive lanes in Taipei City}

Bicycles are beneficial for feeder transport and short distance trips, but $10.2 \%$ of Taipei citizens surveyed were not satisfied with bicycle facilities and felt that biking in Taipei was unsafe. Furthermore, $55.6 \%$ of the citizens who were dissatisfied with the bicycle facilities (MOTC, 2010) indicated that if the Taipei City government provided bicycle exclusive lanes or allowed biking on the sidewalk, they would be willing to bike to work or school. This study proposed a scenario of building bicycle exclusive lanes in Taipei City.

2) Scenario T2: Increasing parking fees for cars and motorcycles in Taipei City

Cars and motorcycles are relatively unsustainable, and MRT and buses are widely distributed in Taipei City. Increasing parking fees for cars and motorcycles is a real-time strategy to push mode shifting. The assessment is based on a $40 \%$ increase in parking fees for all public parking lots.

3) Scenario K1: Building bicycle exclusive lanes in Kaohsiung City

This scenario is the same concept as in Scenario $T 1$ above.

4) Scenario K2: Constructing an infrastructure for electric motorcycles

The transport sustainability of motorcycles is better than that of passenger cars and buses in Kaohsiung City. Encouraging motorcyclists to use electric motorcycles would provide a benefit by reducing environmental impacts, thereby increasing transport sustainability. Constructing an infrastructure for electric motorcycles, e.g., providing charging facilities in parking lots and other locations, is a key factor in making electric motorcycle use more convenient.

The assessment results of the four scenarios are shown in Table 5. The results show that Scenario T1, building exclusive bicycle lanes in Taipei City, would significantly improve the transport sustainability of Taipei (from 0.404 to 0.522 ), particularly in the environmental aspect (from 0.104 to 0.234 ) and social aspect (from 0.681 to 0.921). The improvements of Scenario K1, building exclusive bicycle lanes in Kaohsiung City, would provide improvements similar to those of Scenario T1 in Taipei (from 0.393 to 0.491). The improvements of Scenario T2, increasing parking fees for cars and motorcycles in Taipei City, would be relatively insignificant (from 0.404 to 0.417). The strategy of Scenario K2, constructing an infrastructure for electric motorcycles in Kaohsiung City, would provide the most significant improvements to transport sustainability of any of the four scenarios (from 
0.393 to 0.684$)$.

Table 5. Scenarios for improving transport sustainability

\begin{tabular}{cccccc}
\hline \multicolumn{2}{c}{ City } & Economy & Environment & Society & Transport sustainability \\
\hline \multirow{4}{*}{ Taipei } & Baseline & 0.464 & 0.104 & 0.681 & 0.404 \\
& Scenario T1 & 0.463 & 0.234 & 0.921 & 0.522 \\
& Scenario T2 & 0.468 & 0.112 & 0.710 & 0.417 \\
\hline \multirow{3}{*}{ Kaohsiung } & Baseline & 0.540 & 0.588 & 0.000 & 0.393 \\
& Scenario K1 & 0.540 & 0.709 & 0.185 & 0.491 \\
& Scenario K2 & 0.555 & 1.000 & 0.467 & 0.684 \\
\hline
\end{tabular}

\subsection{Discussion}

Mode-based transport sustainability indicators provide a useful basis for evaluating the comparative advantages of transport modes in terms of economic, environmental, and social considerations. The results support the principle of tailoring measures to fit local circumstances in pursuing transport sustainability.

Compared to the benchmark in Asia, Japan, which has only 0.026 motorcycles per capita, Taiwan's motorcycle ownership ratio is incredibly high ( 0.65 motorcycles per capita). Motorcycles have comparative disadvantages in terms of traffic safety and environmental impacts, but have comparative advantages in travel time and door-to-door service. The comparative disadvantages of motorcycles are externalities and have not been internalized yet. In contrast, trip makers focus on the comparative advantages of motorcycles. These facts cause people (both Taiwanese and foreigners who live in Taiwan) to rely heavily on motorcycles for traveling in Taiwan. A comprehensive evaluation reveals that motorcycles perform the worst in terms of transport sustainability in Taipei City; however, they perform better than cars and buses in terms of transport sustainability in Kaohsiung City. The key factor is that the affordability of transit services in Kaohsiung City is significantly worse than transit affordability in Taipei City. Therefore, the focus of improvement strategies should be on providing negative incentives to push motorcyclists to shift to other modes in Taipei City; and should be on providing positive incentives for green transport (including electric motorcycles) to attract motorcyclists in Kaohsiung City.

Transport sustainability measurement in the environmental aspect reveals that MRT in Kaohsiung City (0.311) performs significantly worse than MRT in Taipei City (0.800). This is reflected in the huge controversy that has arisen in Taiwan over whether MRT in Kaohsiung City is a green transportation mode. This study claims that Kaohsiung City needs to follow the example of Taipei City and extend its MRT network to reach optimum economies of scale, thereby increasing its occupancy rate and reducing its environmental impact intensity.

The case studies of Taipei City and Kaohsiung City confirmed that mode-based transport sustainability indicators could highlight which modes provide comparative advantages in transport sustainability and which strategies could be introduced to improve transport sustainability. The major findings from these two cities confirmed that green transport modes are significantly better than other modes in transport sustainability.

\section{Conclusions}

This study developed a mode-based measurement method that can assess the current transport sustainability of public and private modes at the local level. The case study of Taipei and Kaohsiung confirmed that the mode-based transport sustainability model can highlight which mode provides the most superior transport sustainability and which indicator or aspect should be improved to enhance the transport sustainability of different cities.

A weighting scheme was incorporated into the group decision making process to aggregate nine indicators. The findings from Taipei and Kaohsiung reveal that the use of MRT and bicycles significantly improves transport sustainability, but that the effect of motorcycle use on transport sustainability varies according to local circumstances. The results of the analysis of the four scenarios indicate that building bicycle exclusive lanes would have significant environmental and social benefits in both Taipei and Kaohsiung. Increasing parking fees for cars and motorcycles would have a relatively insignificant effect on improving the sustainability in Taipei City. Constructing an infrastructure for electric motorcycles in Kaohsiung would provide the most significant improvement to transport sustainability of any of the four scenarios.

The issue of motorcycle management has attracted the attention of researchers in Taiwan due to the popular use 
of motorcycles for transportation and the related environmental and social impacts. The results of mode-based transport sustainability measurement can be provided as policy guidelines for different cities. Additionally, the comparison of transport sustainability for MRT in Taipei and Kaohsiung Cities can also be used as a reference to evaluate the projected MRT extension in Kaohsiung City.

Enhancing modal shift or using alternative energy is an effective way to improve transport sustainability based on this case study of Taipei and Kaohsiung. Using social construction of technology (SCOT) (Note 1) combined with improvement strategies to reinforce public participation would be a valuable research direction in the future. Another subject related to the comparison between transport sustainability and transport quality of life would also be a prior future research. Trade-off between social responsibility and people's perception could be a compromise way to guide policy direction.

\section{References}

Amekudzi, A. A., Khisty, C. J., \& Khayesi, M. (2009). Using the sustainability footprint model to assess development impacts of transportation systems. Transportation Research Part A, 43(4), 339-348. http://dx.doi.org/10.1016/j.tra.2008.11.002

Carse, A. (2011). Assessment of transport quality of life as an alternative transport appraisal technique. Journal of Transport Geography, 19(5), 1037-1045. http://dx.doi.org/10.1016/j.jtrangeo.2010.10.009

Clayton, M. J. (1997). Delphi: a technique to harness expert opinion for critical decision-making tasks in education. Educational Psychology, 17(4), 373-386. http://dx.doi.org/10.1080/0144341970170401

Dudson, B. (1998). When cars are clean and clever: A forward-looking view of sustainable and intelligent automobile technologies. Transportation Quarterly, 52(3), 103-120.

ECMT. (2004). Assessment and decision making for sustainable transport. ECMT, OECD. Retrieved from http://www.oecd.org

EEA. (2001). TERM 2001 Indicators tracking transport and environment integration in the European Union. Copenhagen (Denmark): EEA.

EEA. (2011). Laying the foundations for greener transport -TERM 2011: transport indicators tracking progress towards environmental targets in Europe. Copenhagen (Denmark): EEA.

Elle, M., Dammann, S., Lentsch, J., \& Hansen, K. (2010). Learning from the social construction of environmental indicators: From the retrospective to the pro-active use of SCOT in technology development. Building and Environment, 45(1), 135-142. http://dx.doi.org/10.1016/j.buildenv.2009.05.011

Givoni, M. (2007). Environmental benefits from mode substitution: Comparison of the environmental impact from aircraft and high-speed train operations. International Journal of Sustainable Transportation, 1(4), 209-230. http://dx.doi.org/10.1080/15568310601060044

Kennedy, C. A. (2002). A comparison of the sustainability of public and private transportation systems: Study of the Greater Toronto Area. Transportation, 29(4), 459-493. http://dx.doi.org/10.1023/A:1016302913909

Leontief, W. W. (1986). Input-output economics. New York, NY: Oxford University Press.

Litman, T. (2007). Developing indicators for comprehensive and sustainable transport planning. Transportation Research Record, 2017, 10-15. http://dx.doi.org/10.3141/2017-02

Ministry of Transportation and Communications (MOTC). (2010). Survey on bicycle use (in Chinese). Taipei (Taiwan): MOTC. Retrieved from http://www.motc.gov.tw/ch/index.jsp

Qin, J., Weissmann, J., Euritt, M. A., \& Martello, M. (1996). Evaluating the full cost of urban passenger transportation. Transportation Research Record, 1518, 57-64. http://dx.doi.org/10.3141/1518-11

Saaty, T. L. (1980). The analytic hierarchy process: Planning, priority setting, resource allocation. New York, NY: McGraw-Hill.

Shiau, T. A. (2012). Evaluating sustainable transport strategies with incomplete information for Taipei City. Transportation Research Part D, 17(6), 427-432. http://dx.doi.org/10.1016/j.trd.2012.05.002

\section{Notes}

Note 1. Social construction of technology (SCOT) is a theory (or methodology) within the field of science and technology studies (STS). What SCOT shows is that technology does not determine human action, but that rather, human action shapes technology. Elle, Dammann, Lentsch, and Hansen (2010), for example, compared two kinds of the use of SCOT in developing environmental indicators for buildings. 